\title{
Multiple fluid migration events evidenced in pyroxenites of the Cabo Ortegal Complex (NW-Spain)
}

\author{
T. SPRÁNITZ ${ }^{1 *}$, M. BERKESI ${ }^{1}$ AND CS. SZABÓ ${ }^{1}$
}

${ }^{1}$ Lithosphere Fluid Research Lab, Department of Petrology and Geochemistry, Eötvös University, Budapest, Hungary (*correspondence: spratom.elte@gmail.com)

Metamorphic rocks of exhumed high pressure terranes, such as the Cabo Ortegal Complex (COC), preserve direct evidences of fluid-rock interactions during subduction zone processes. Ultramafic rocks of the COC are mainly composed of harzburgites with abundant layers of piroxenites, which are thought to have been formed in subarc lithospheric mantle depth, afterwards introduced into a Variscan subduction channel [1]. Our study aims to characterize secondary fluid inclusions in these rocks, which provides an insight into fluid migration during retograde reactions and serpentinization in a subduction channel.

Pyroxenites in this study were sampled from both main mantle sections of the COC (i.e. Herbeira and Limo Massif) and show various degrees of amphibolization and serpentinization. Clinopyroxene, amphibole and garnet host several types of secondary inclusions, which were trapped before and during serpentinization, based on petrography, microthermometry and Raman spectroscopy. More than three type of secondary fluid inclusions predate antigorite veins and are composed of carbonates and volatiles such as methane and nitrogen. They are 1-8 $\mu \mathrm{m}$ sized showing elongated or negative crystal shape. Raman imaging showed that carbonates generally fill more than $50-60$ vol. $\%$ of the inclusion volume. Relative concentration of $\mathrm{CH}_{4}$ and $\mathrm{N}_{2}$ are consistent within each type of the inclusions, however, shows variations between them $\left(\mathrm{CH}_{4}\right.$ 10-85 mol. \%, $\mathrm{N}_{2}$ 15-90 mol. $\%$ ). The most abundant type of secondary fluid inclusions are texturally associated with serpentine veins. These inclusions are characterized by an irregular, ratty shape with variable sizes $(1-40 \mu \mathrm{m})$. They are liquid-rich aqueous two phase inclusions at room temperature with $\mathrm{CH}_{4}$ in the vapor phase.

Our results impy that migration of metamorphic fluids occurred at several stages during retrograde evolution of the COC. In addition, we point to the $\mathrm{CH}_{4}$-rich aqueous inclusions as direct records of a pervasive serpentinizing fluid released within the subduction channel.

This work was supported by the ÚNKP-19-3 New National Excellence Program of the Ministry for Innovation and Technology.

[1] Tilhac et al. (2016) J Petrol 57, 1921-1954. 